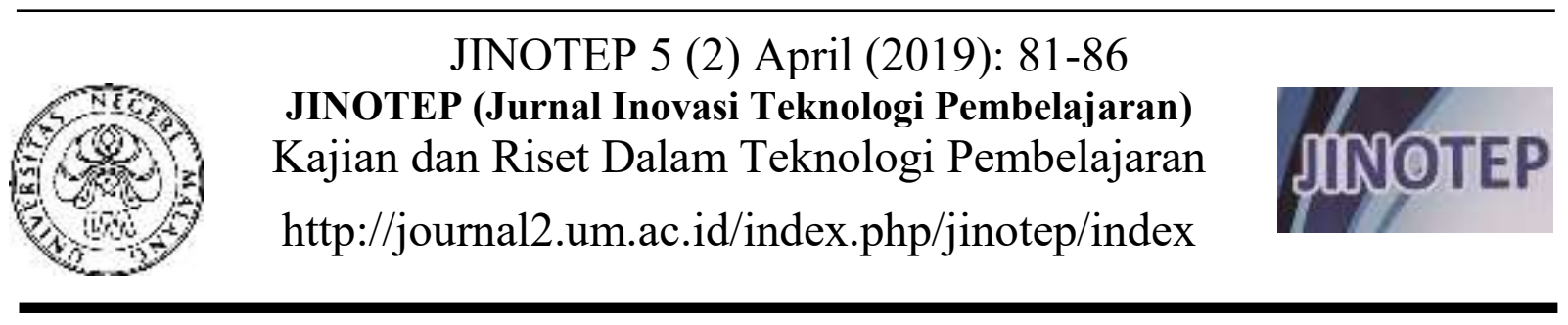

\title{
PENGEMBANGAN VIDEO PEMBELAJARAN KALOR UNTUK SISWA KELAS VII
}

\author{
Ardiyanti Ulyana, Zainul Abidin, Arafah Husna \\ Universitas Negeri Malang
}

\section{Article History \\ Received: March 21, 2019 \\ Accepted: April 30, 2019 \\ Published: April 30, 2019}

\section{Keywords}

Development, Media,

Instructional Video, Calor

\begin{abstract}
Abstrak
Tujuan dari pengembangan yaitu menghasilkan produk media video pembelajaran yang valid sebagai sumber belajar yang efektif dalam mata pelajaran IPA materi pokok Kalor kelas VII C. Penelitian ini menggunakan model pengembangan Sadiman. Peneliti memilih model Sadiman karena model ini dirancang untuk mengembangkan media pembelajaran berupa audio, video dan film. Selain itu model pengemba-ngan ini sistematis dan sederhana sehingga mudah untuk dikontrol di setiap langkahnya. Adapun langkah-langkah yang dilakukan (1) identifikasi kebutuhan, (2) perumusan tujuan, (3) perumusan butirbutir materi, (4) perumusan alat pengukur keberhasilan, (5) penulisan naskah media, (6) produksi, (7) uji coba, (8) revisi, dan (9) media siap pakai.
\end{abstract}

\begin{abstract}
The purpose of development is to produce a valid instructional video media as a source of effective learning in science this topic of Calor in Seventh Grade class C. This research uses model of development Sadiman. Researchers chose Sadiman models because this model is designed to develop learning media such as audio, video and film. Besides the development model is a systematic and simple, so easy to be controlled at every step. The steps is, (1) Need assessment, (2) The formulation of objectives, (3) the formulation of the material, (4) the formulation gauges success, (5) scriptwriting media, (6) production, (7) trials, (8) the revision, and (9) media ready to use.
\end{abstract}

Corresponding author :

Ardiyanti Ulyana,

Adress: Jalan Semarang No. 5 Malang,

Instansi: Teknologi Pendidikan Universitas Negeri Malang

E-mail: alya.ariez@gmail.com
2019 Universitas Negeri Malang p-ISSN 2406-8780 e-ISSN 2654-7953 


\section{PENDAHULUAN}

Ilmu Pengetahuan Alam (IPA) merupakan ilmu yang materi pokoknya adalah alam dan segala isinya (Pusat Kurikulum, 2006:4). Secara umum IPA di Sekolah Menengah Pertama/Madrasah Tsanawiyah (SMP/MTs), meliputi bidang kajian energi dan perubahannya, bumi antariksa, makhluk hidup dan proses kehidupan,dan materi dan sifatnya yang sebenarnya sangat berperan dalam membantu siswa untuk memahami fenomena alam (Sutedjo: 2007). Siswa diajak untuk berpikir secara luas dan mendalam untuk menangkap dan memahami hubungan-hubungan konseptual yang disajikan untuk mencapai tujuan hasil belajar pada aspek kognitif.

Pada teori perkembangan kognitif Piaget, siswa SMP/MTs termasuk kelompok individu yang sudah mencapai tahap operasional formal dengan usia 11 tahun sampai dewasa (Slavin, 2008).. Tahap operasional formal merupakan tahap final perkembangan kognitif, pada tahap ini prosesproses penalaran logis diterapkan ke ide-ide abstrak ataupun ke objek-objek konkret (Jeanne, 2009:47). Karakteristik tahap ini adalah diperolehnya kemampuan untuk berpikir secara abstrak, menalar secara logis, dan menarik kesimpulan dari informasi yang tersedia.

Berdasarkan sumber dari Balitbang Depdiknas (Puskur, 2006:7) pembelajaran IPA yang disajikan secara disiplin keilmuan dianggap terlalu dini bagi siswa usia 7-14 tahun, karena siswa pada usia ini masih dalam masa transisi dari tingkat berpikir operasional konkrit ke berpikir abstrak/tahap operasional formal. Hal ini bisa dipengaruhi oleh beberapa faktor seperti faktor eksternal (lingkungan luar) bahwa kemampuan dalam belajar siswa berbeda-beda dalam menerima dan merespons.

Pada dasarnya, dalam proses pembelajaran IPA, masing-masing siswa memberikan respon yang berbeda-beda terhadap sumber informasi yang disampaikan oleh guru. Hasil yang diperoleh dari wawancara kepada beberapa siswa kelas VII C di MTs Wahid Hasyim 2 Dau Malang pada tanggal 25 Januari 2016, diketahui bahwa siswa masih kesulitan dalam memahami sajian materi IPA karena minimnya sumber belajar yang digunakan hanya buku paket. Sumber belajar tersebut belum mengatasi beberapa materi yang dirasakan abstrak dan cukup sulit untuk dipahami oleh siswa. Salah satunya adalah materi pokok kalor yang masih bersifat abstrak, pada materi pokok ini terdapat penjelasan konsep mengenai fenomenafenomena sehari-hari, yaitu kalor dapat mengubah wujud zat, perpindahan kalor, dan pemanfaatan kalor dalam kehidupan sehari-hari.

Berdasarkan hasil wawancara pada tanggal 26 Januari 2016 dengan guru mata pelajaran IPA dan pengamatan langsung di MTs Wahid Hasyim 2 Dau Malang, diketahui beberapa permasalahan pada proses pembelajaran IPA materi pokok Kalor yaitu: 1) keterbatasan media serta waktu dalam proses pembelajaran karena sumber belajar siswa hanya diperoleh dari guru dan buku pelajaran IPA yang berisi materi dan visualisasi gambar, 2) siswa mengalami kesulitan dalam penguasaan konsep materi pokok kalor yang bersifat abstrak, dan 3) siswa tidak dapat mencapai kompetensi yang diharapkan, yang mana pada nilai ujian semester mata pelajaran IPA masih banyak yang nilainya dibawah ratarata dengan Kriteria Ketuntasan Minimal $(\mathrm{KKM})>70$ menurut Guru IPA MTs Wahid Hasyim 02 Dau Malang. Pada materi pokok Kalor berisi empat bahasan materi utama yaitu: 1) pengertian kalor, 2) kalor mengubah wujud zat, 3) perpindahan kalor, dan 4) pemanfaatan kalor.

Berdasarkan masalah pada aspek kognitif siswa yang berbeda dalam menerima dan merespons informasi yang disampaikan guru, dibutuhkan suatu media audio-visual yang dapat membuat siswa mencapai tujuan pembelajaran dengan menyajikan kepada siswa tentang materi pokok Kalor sesuai dengan standar kompetensi, kompetensi dasar, indikator dan tujuan pembelajaran yaitu dengan media video pembelajaran.

Video pembelajaran adalah salah satu alternatif media pembelajaran elektronik yang dapat memuat wawasan dan pengetahuan mengenai teori dan penerapan materi dalam kehidupan sehari-hari (Rahmat, 2012: 21). Dengan membuat video pembelajaran yang didalamnya menjelaskan beberapa percobaan sederhana dengan alat-alat yang didapat dari kehidupan sehari-hari, dapat meningkatkan 
pemahaman siswa dalam konsep IPA secara kongkret/nyata

\section{METODE}

Model pengembangan sadiman, yang meliputi (1) identifikasi kebutuhan, (2) perumusan tujuan, (3) perumusan butir-butir materi, (4) perumusan alat pengukur keberhasilan, (5) penulisan naskah media, (6) produksi, (7) uji coba, (8) revisi, dan (9) media siap pakai. Peneliti memilih model Sadiman karena model ini dirancang untuk mengembangkan media pembelajaran, selain itu model pengembangan ini sistematis sehingga mudah untuk dikontrol di setiap langkahnya. Rancangan pengembangan penelitian dalam bentuk flowchart, maka langkah-langkahnya sebagai berikut:

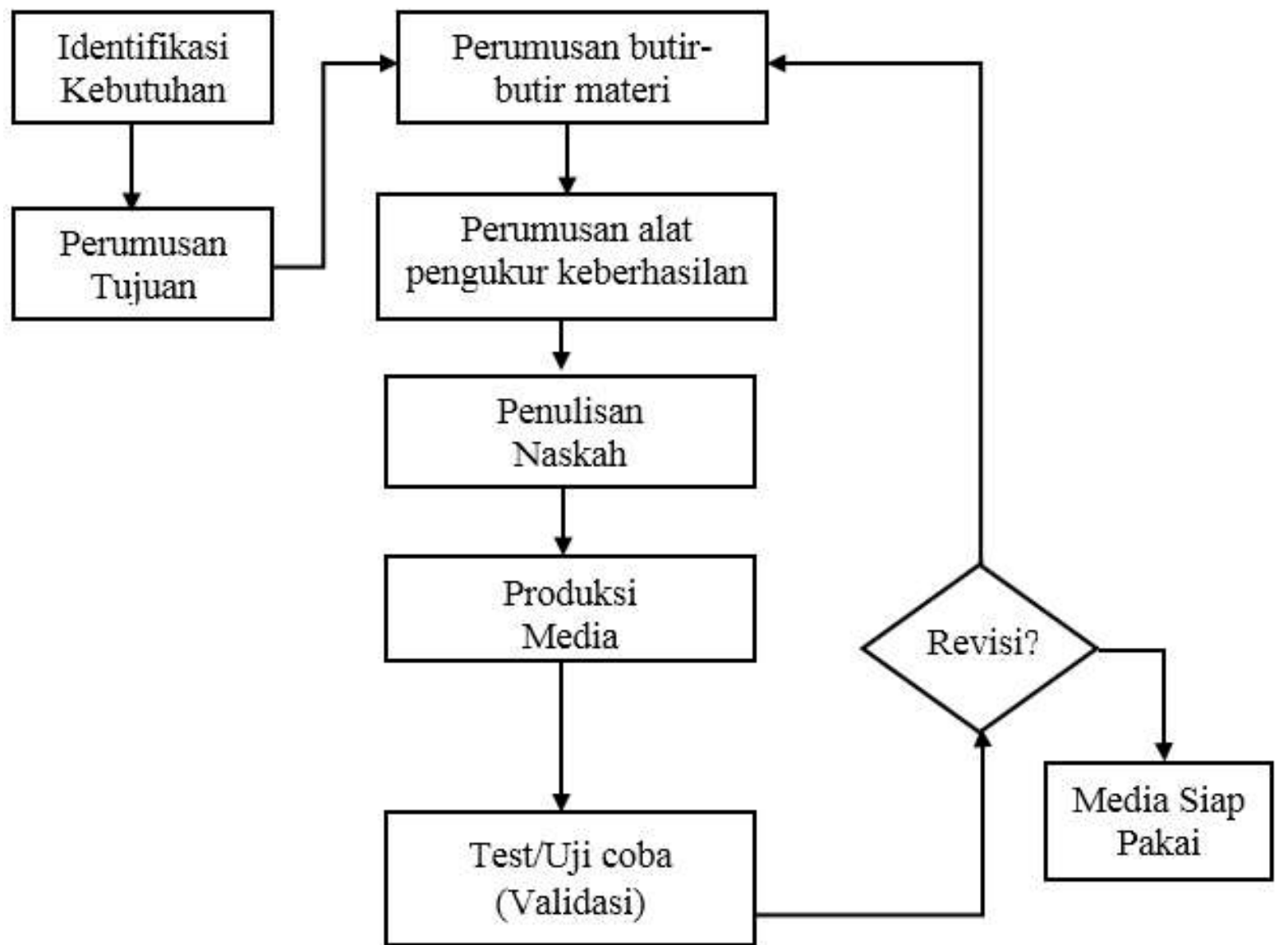

Gamabr 1. Bagan Model Pengembangan Media (Sadiman, dkk., 2014:101)

Video pembelajaran ini divalidasikan kepada ahli media dan ahli materi sebelum diujicobakan kepada subjek penelitian. Subjek penelitian dalam pengembangan multimedia interaktif ini adalah siswa kelas VII MTs Wahid Hasyim 2 Dau Malang. Video pembelajaran ini divalidasikan pada ahli media untuk melihat kevalidan multimedia interaktif jika digunakan dalam pembelajaran. Sedangkan pada ahli materi untuk melihat kevalidan materi yang terdapat pada video pembelajaran. Desain uji coba yang digunakan yaitu ujicoba perseorangan dengan jumlah 3 siswa, uji coba kelompok kecil dengan jumlah 10 siswa, dan uji coba lapangan dengan jumlah 20 siswa.
Penelitian pengembangan ini menggunakan beberapa instrumen untuk mengumpulkan data, antara lain: observasi, wawancara, angket, tes, dan dokumentasi

\section{Analisis Data Angket}

1. Rumus perhitungan data angket (ahli media, ahli materi, dan siswa) (Arikunto,2006)

$$
P=\frac{\sum s 0}{\sum s . M a k s} \times 100 \%
$$

Keterangan : 
84 JINOTEP (Jurnal Inovasi dan Teknologi Pembelajaran) Kajian dan Riset dalam Teknologi Pembelajaran Vol. 5, No. 2, April 2019, Hal. 81-86

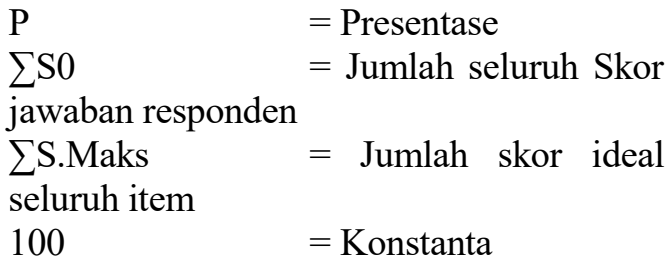

2. Rumus untuk mengolah hasil pre-test dan post-test

Adapun pengolahan datanya ditentukan sebagai berikut:

a) Pengolahan data sebelum menggunakan video pembelajaran :

(1) Menentukan SKM (Standar Ketuntasan Minimum), yaitu $>70$

(2) Menghitung jumlah siswa yang memenuhi SKM (\%) (Arikunto, 2006) :

$$
P=\frac{\sum X}{\sum X i} \times 100 \%
$$

Keterangan :

$$
\begin{array}{ll}
\mathrm{P} & =\text { Presentase } \\
\sum_{\text {Siswa yang memenuhi SKM }} & =\text { Jumlah kesuluran } \\
\sum_{\text {Siswa }} \mathrm{Xi} & \text { Jumlah keseluruhan } \\
100 & =\text { Konstanta }
\end{array}
$$

(3) Menghitung jumlah siswa yang tidak memenuhi SKM (\%)(Arikunto, 2006) :

$$
\mathbf{P}=\frac{\sum X}{\sum X i} \times 100 \%
$$

Keterangan :

$$
\begin{array}{ll}
\mathrm{P} & =\text { Presentase } \\
\sum \mathrm{X} & =\text { Jumlah kesuluran }
\end{array}
$$

siswa yang tidak memenuhi SKM

$\sum \mathrm{Xi} \quad=$ Jumlah keseluruhan siswa

$100=$ Konstanta

(4) Menghitung tingkat presentase kenaikan hasil belajar

b) Pengolahan data sesudah menggunakan video pembelajaran :

(1) Menentukan SKM (Standar Ketuntasan Minimum), yaitu $>70$

(2) Menghitung jumlah siswa yang memenuhi SKM (\%) (Arikunto, 2006) :

$$
\mathbf{P}=\frac{\sum X}{\sum X i} \mathbf{x} 100 \%
$$

Keterangan :

$$
\begin{array}{ll}
\mathrm{P} & =\text { Presentase } \\
\sum \mathrm{X} & =\text { Jumlah kesuluran }
\end{array}
$$

siswa yang memenuhi SKM

$\begin{array}{ll}\sum_{\text {siswa }} \mathrm{Xi} & =\text { Jumlah keseluruhan } \\ 100 & =\text { Konstanta }\end{array}$

(3) Menghitung jumlah siswa yang tidak memenuhi SKM (\%)(Arikunto, 2006) :

$$
\mathbf{P}=\frac{\sum X}{\sum X i} \times 100 \%
$$

Keterangan :

$$
\begin{array}{ll}
\mathrm{P} & =\text { Presentase } \\
\sum \mathrm{X} & =\text { Jumlah kesuluran }
\end{array}
$$

\begin{tabular}{|c|c|c|c|}
\hline Kategori & $\begin{array}{l}\text { Presentase } \\
(\%)\end{array}$ & Keterangan & Skor \\
\hline A & $81-100$ & Valid & 4 \\
\hline B & $61-80$ & Cukup Valid & 3 \\
\hline $\mathrm{C}$ & $41-60$ & $\begin{array}{l}\text { Kurang } \\
\text { Valid }\end{array}$ & 2 \\
\hline $\mathrm{D}$ & $<40$ & Tidak Valid & 1 \\
\hline
\end{tabular}

siswa yang tidak memenuhi SKM

$\sum \mathrm{Xi} \quad=$ Jumlah keseluruhan siswa

$100=$ Konstanta

(4) Menghitung tingkat presentase kenaikan hasil belajar

$$
P=\frac{\sum d}{\sum N i} \times 100 \%
$$

Keterangan :

$$
\begin{aligned}
& \mathrm{P} \quad=\text { Presentase } \\
& \sum \mathrm{d} \quad=\text { Jumlah total } \\
& \text { kenaikan hasil tes } \\
& \sum \mathrm{Xi} \quad=\text { Jumlah total nilai } \\
& \text { ideal kesuluruhan siswa } \\
& 100=\text { Konstanta }
\end{aligned}
$$

Setelah didapat hasil dari data dikelola dengan menggunakan rumus diatas maka hasil tersebut dicocokkan denga kriteria tingkat kevalidan sebagai berikut:

Tabel 1. Kreteria kevalidan (Arikunto, 2010:35)

Keterangan : 
UlyanA - Pengembangan Video Pembelajaran...85

a) Apabila hasil analisis memperoleh kreteria A $(81 \%-100 \%)$ maka media tersebut termasuk kualifikasi valid dan layak digunakan untuk pembelajaran dikelas

b) Apabila hasil analisis memperoleh kreteria $\mathrm{B}$ $(61 \%-80 \%)$ maka media tersebut termasuk kualifikasi cukup valid dan layak digunakan untuk pembelajaran dikelas

c) Apabila hasil analisis memperoleh kreteria $\mathrm{C}$ $(41 \%-60 \%)$ maka media tersebut termasuk kualifikasi kurang valid dan media harus direvisi. Artinya tidak layak digunakan untuk pembelajaran dikelas

d) Apabila hasil analisis memperoleh kreteria D $(<40 \%)$ maka media tersebut termasuk kualifikasi tidak valid dan harus diganti.

Media video pembelajaran yang dikembangkan dikatakan berhasil dan dapat dimanfaatkan sebagai media pembelajaran apabila mencapai kreteria cukup layak dan valid $(61 \%-80 \%)$.

Video Pembelajaran dapat dikatakan berhasil jika skor tes hasil belajar yang diperoleh siswa melebihi KKM. KKM dalam pembelajaran Ilmu Pengetahuan Alam adalah $\geq$ 70. Maka data tes hasil belajar dari jumlah siswa yang memenuhi KKM harus lebih dari $80 \%$ agar video pembelajaran dapat digunakan untuk guru maupun untuk siswa dalam pembelajaran.

Tabe 2. Kriteria Tingkat Keberhasilan Tes Hasil Belajar (Arikunto, 2010)

\begin{tabular}{lll}
\hline Kategori & Presentase & Keterangan \\
\hline $\mathrm{A}$ & $80-100$ & Efektif \\
$\mathrm{B}$ & $60-79$ & Cukup Efektif \\
$\mathrm{C}$ & $40-59$ & Kurang Efektif \\
$\mathrm{D}$ & $<40$ & Tidak Efektif \\
\hline
\end{tabular}

\section{HASIL DAN PEMBAHASAN}

Berdasarkan hasil penyebaran angket kepada tiga responden, yakni 1 orang ahli media, 1 orang ahli materi, uji coba satu lawan satu sebanyak 3 siswa, uji coba kelompok kecil sebanyak 10 siswa, dan uji coba lapangan sebanyak 20 siswa, maka dapat diinterpretasikan pada tabel 3 .

Setelah dilakukan validasi, kemudian dilanjutkan dengan tes hasil belajar untuk mengetahui tingkat kelayakan atau keefektifan penggunaan multimedia interaktif, produk ini dinyatakan efektif. Hal ini terbukti dari hasil pengolahan nilai hasil belajar seluruh siswa kelas VII MTs Wahid Hasyim 2 Dau Malang memenuhi KKM (>70) pembelajaran Ilmu Pengetahuan Alam.

Tabel 3. Hasil Validasi

\begin{tabular}{|c|c|c|c|}
\hline No. & Responden & $\begin{array}{l}\text { Rata- } \\
\text { rata }\end{array}$ & Kreteria \\
\hline 1 & Ahli Media & $89,50 \%$ & Valid \\
\hline 2 & Ahli Materi & $96.25 \%$ & Valid \\
\hline 3 & $\begin{array}{l}\text { Uji Coba } \\
\text { perseorangan }\end{array}$ & $90,47 \%$ & Valid \\
\hline 4 & $\begin{array}{l}\text { Uji } \quad \text { Coba } \\
\text { Kelompok Kecil }\end{array}$ & $91,60 \%$ & Valid \\
\hline 5 & $\begin{array}{ll}\text { Uji } & \text { Coba } \\
\text { Lapangan } & \end{array}$ & $91,10 \%$ & Valid \\
\hline
\end{tabular}

Media yang dikembangkan hanya di uji sampai tahap validasi kelayakan, sehingga tidak sempat dilakukan pengujian lapangan. Hal ini merupakan salah satu kelemahan dari media yang dikembangkan. Namun demikian berdasarkan hasil penelitian yang sejenis, diperoleh beberapa simpulan yang secara umum menyatakan bahwa media video bermanfaat dan mendukung capaian kompetensi pembelajaran. Kurniawan (2018) menyatakan bahwa media video yang layak dapat meningkatkan hasil belajar siswa. Hal itu senada dengan temuan penelitian Alamsyah (2018) yang menyatakan bahwa media video dapat mendukung kegiatan pembelajaran yang menarik bagi siswa (Luhulima, 2018). Pernyataan yang senada di sampaikan oleh Hapsari (2018) yang menyebutkan bahwa media video yang memenuhi prinsip multimedia dapat meningkatkan motivasi belajar dan hasil belajar siswa.

\section{SIMPULAN DAN SARAN}

Berdasarkan pada hasil pengembangan video pembelajaran untuk mata pelajaran Ilmu Pengetahuan Alam materi pokok Kalor MTs Wahid Hasyim 2 Dau Malang, menunjukkan bahwa video pembelajaran ini valid dan layak untuk digunakan sebagai media pembelajaran.

Agar produk yang dihasilkan dapat dimanfaatkan secara maksimal dalam kegiatan pembelajaran, maka ada beberapa saran yang terkait dengan video pembelajaran mata pelajaran Ilmu Pengetahuan Alam materi pokok Kalor antara lain: (1) Bagi Guru, untuk kelancaran proses kegiatan pembelajaran menggunakan video pembelajaran, sebaiknya guru sudah mempersiapkan alat-alat pendukung yaitu dengan menyiapkan komputer/laptop yang memiliki fasilitas CD ROM dan dapat menyiapkan LCD projektor, serta membaca 
86 JINOTEP (Jurnal Inovasi dan Teknologi Pembelajaran) Kajian dan Riset dalam Teknologi Pembelajaran Vol. 5, No. 2, April 2019, Hal. 81-86

buku petunjuk pemanfaatan dengan cermat agar tidak menemui kendala dalam mengoperasikan video pembelajaran; (2) Bagi siswa: Dalam penggunaan video pembelajaran ini siswa aktif dan mengikuti petunjuk yang diberikan oleh guru dalam pembelajaran agar tujuan pembelajaran dapat tercapai sesuai dengan yang diharapkan.

\section{DAFTAR RUJUKAN}

Alamsyah, R., Toenlioe, A. J., \& Husna, A. (2019). Pengembangan video pembelajaran kepenyiaran materi produksi program televisi untuk mahasiswa Teknologi Pendidikan Universitas Negeri Malang. Jurnal Kajian Teknologi Pendidikan, 1(3), 229-236.

Arikunto, Suharsimi. 2006. Prosedur Penelitian Suatu Pendekatan Praktek. Jakarta: PT Rieka Cipta.

Arikunto, Suharsimi. 2010. Prosedur Penelitian Suatu Pendekatan Praktek. Jakarta: PT Rieka Cipta.

Hapsari, N. D., Toenlioe, A. J., \& Soepriyanto, Y. (2019). Pengembangan Augmented Reality Video Sebagai Suplemen Pada Modul Bahasa Isyarat. Jurnal Kajian Teknologi Pendidikan, 1(3), 185-194.

Kurniawan, D. C., Kuswandi, D., \& Husna, A. (2018). Pengembangan media video pembelajaran pada mata pelajaran IPA tentang sifat dan perubahan wujud benda kelas IV SDN Merjosari 5 Malang. JINOTEP (Jurnal Inovasi dan Teknologi Pembelajaran): Kajian dan Riset Dalam Teknologi Pembelajaran, 4(2), 119-125.

Luhulima, D. A., Degeng, N. S., \& Ulfa, S. (2018). Pengembangan Video Pembelajaran Karakter Mengampuni Berbasis Animasi Untuk Anak Sekolah Minggu. JINOTEP (Jurnal Inovasi dan Teknologi Pembelajaran): Kajian dan Riset Dalam Teknologi Pembelajaran, 3(2), 110-120.

Pusat Kurikulum.(2006). Buram Panduan Pengembangan Pembelajaran IPA Terpadu. (Online), (http://www.academia.edu), diakses 24 Januari 2016

Rahmat, Cecep. 2012. Pengembangan Video Pembelajaran IPA (Fisika) Berbasis Pendekatan Lingkungan sebagai Media Pembelajaran untuk SMP/MTs. (Online), (http://digilib.uin-suka.ac.id/), Diakses 25 Januari 2016

Sadiman, Arief. 2014. Media Pendidikan, Pengertian, Pengembangan, dan Pemanfaatannya. Jakarta: Raja Grapindo Persada

Slavin, Robert E. 2008. Psikologi Pendidikan Teori dan Praktik Edisi Kedelapan (Marianto Samosir, Ed.). Jakarta: PT Indeks.

Sutedjo, Bambang. Panduan Pengembangan Pembelajaran IPA Terpadu SMP/MTs, Pusat Kurikulum, Balitbang Depdiknas. 